\title{
Curcumin Inhibits Prostate Cancer Bone Metastasis by Up-Regulating Bone Morphogenic Protein-7 in Vivo
}

\author{
Thambi Dorai1 ${ }^{*}$, Janane Diouri², Orla 0'Shea2, Stephen B. Doty2* \\ ${ }^{1}$ Department of Urology, New York Medical College, Valhalla, USA \\ ${ }^{2}$ Analytical Microscopy Laboratory, Hospital for Special Surgery, New York, USA \\ Email: thambi dorai@nymc.edu, ㅁotyS@HSS.EDU
}

Received 7 February 2014; revised 5 March 2014; accepted 12 March 2014

Copyright $@ 2014$ by authors and Scientific Research Publishing Inc.

This work is licensed under the Creative Commons Attribution International License (CC BY). http://creativecommons.org/licenses/by/4.0/

(C) (i) Open Access

\section{Abstract}

A number of studies have focused on the beneficial properties of Curcumin (diferuloyl methane, used in South Asian cuisine and traditional medicine) such as the chemoprevention of cancer. Recent studies have also indicated that this material has significant benefits for the treatment of cancer and is currently undergoing several clinical trials. We have been interested in the application of this compound as a therapeutic agent for advanced prostate cancer, particularly the skeletal complications in this malignancy. Our earlier work indicated that this compound could inhibit the osteomimetic properties which occur in castration resistant prostate cancer cells, by interfering with the common denominators between these cancer cells and the bone cells in the metastatic tumor microenvironment, namely the osteoblasts and the osteoclast. We predicted that curcumin could break the vicious cycle of reciprocal stimulation that results in uncontrolled osteolysis in the bony matrix. In this work, we have evaluated the potential of this compound in inhibiting the bone metastasis of hormone refractory prostate cancer cells in an established animal model. Our results strongly suggest that curcumin modulates the TGF- $\beta$ signaling that occurs due to bone matrix degradation by up-regulating the metastasis inhibitory bone morphogenic protein-7 (BMP7). This enhancement of BMP-7 in the context of TGF- $\beta$ in the tumor microenvironment is shown to enhance the mesenchymal-to-epithelial transition. Most importantly, we show that as a result of BMP-7 up-regulation, a novel brown/beige adipogenic differentiation program is also up-regulated which plays a role in the inhibition of bone metastasis. Our results suggest that curcumin may subvert the TGF- $\beta$ signaling to an alternative adipogenic differentiation program in addition to the previously established interference with the osteomimetic properties, thus inhibiting the bone metastatic processes in a chemopreventive as well as therapeutic setting.

\footnotetext{
${ }^{*}$ Corresponding authors.
} 


\section{Keywords}

\section{Curcumin, Osteomimetic Properties, Bone Metastasis, Bone Morphogenic Protein-7, TGF- $\beta$, Prostate Cancer, Tumor Microenvironment}

\section{Introduction}

Despite its common occurrence and extensive research, prostate cancer biology and its metastasis are still poorly understood [1] [2]. Bone is the most favored metastatic site in prostate cancer cases producing lesions which are predominantly osteoblastic but yet osteosclerotic in appearance. Epidemiological studies indicate that while the rate of occurrence of clinically indolent prostate cancer is similar worldwide, the rate of occurrence of clinically significant and metastatic prostate cancer is markedly lower in Asia than in western populations [3]-[6]. It has been proposed that these differences are largely due to influencing factors such as diet and nutrition rather than genetic variations because Asian men who adopt a western lifestyle show an increased incidence of clinically significant disease [7] [8]. While several studies have been conducted to investigate the role of dietary components such as soy, resveratrol and green tea etc. on prostate cancer growth, so far very few of these studies have focused on interfering with the metastatic complications in prostate cancer by dietary ingredients [9]-[11]. This clearly represents a gap in our knowledge and emphasizes the importance of testing such agents that would prevent the skeletal metastatic outcome so as to improve the quality of life in the patient in a safe and non-toxic manner. Advanced prostate cancer is invariably treated by some form of androgen deprivation therapy [12] [13]. Unfortunately, today the clinicians know that hormonal deprivation therapy is at best palliative and not a very effective treatment for prostate cancer. There is also an increasing belief that stringent selective pressure imposed by androgen deprivation on the residual prostate cancer cells might actually accelerate the development of more aggressive, metastatic and rapidly growing prostate cancers [14]-[16]. Therefore, the search for a reliable mechanism based treatment strategies continues. Several investigators have recently turned towards strategies in complementary and alternative medicine, tapping into the vast traditional knowledge base available in various ethnic societies. Over the past few years, a number of foods, vitamins and minerals have been found to be beneficial for the prevention and treatment of prostate cancer [17] [18]. Evidence is mounting that we can prevent many illnesses such as prostate cancer by modifying our lifestyle, for example, by diet [19] [20]. Hence, the use of nutritional modification as a preventive modality or as an adjuvant therapy for the treatment of prostate cancer is an attractive idea [21] [22]. This study focuses on the possible therapeutic efficacy of the dietary ingredient curcumin, used in traditional medicine and in the cuisine of India and South East Asia for centuries as a powerful anti-oxidant, as an anti-inflammatory agent and as a flavor enhancer.

We have investigated over several years the possibility that the naturally occurring chemopreventive compound called curcumin (diferuloyl methane) could also be used in a therapeutic manner to slow down the progression of prostate cancer, particularly the establishment of bony metastases [23]-[27]. This material is widely used in South East Asia in traditional medicine and as a culinary flavor enhancer [28]-[30]. Our preliminary results strongly indicated that this agent might interfere with several signaling pathways that contribute to the metastatic potential of these prostate cancer cells. To investigate this, we have used the C4-2B prostate carcinoma bone metastasis progression model system developed by Chung and his coworkers [31]-[33]. This is an ideally suited system since it mimics all the features of androgen independent growth, a preferred osseous metastatic potential and in the exhibition of osteomimetic properties. By acquiring these osteomimetic properties, these prostate cancer cells draw a parallel between their own function/progression and osteoblast/osteoclast function and maturation, in order to survive in the bony microenvironment. This model system also emphasizes the importance of the collaboration between the prostate cancer cells and bone stromal cells which is based on a common growth factor environment and requirement for these cell types. Our preliminary results indicated that curcumin is capable of interfering with both the osteoblastic and the osteoclastic component of the mimicry that these prostate cancer cells exhibit in order to reside and proliferate in the bony metastases [26]. This is mainly shown by the observations that curcumin is capable of inhibiting the signaling pathways mediated by epidermal growth factor receptor and macrophage colony stimulation factor-1 receptor, inhibition of the expression of osteoblast specific transcription factor Cbfa-1 and finally by inhibiting the activation process of the transcription 
factor NF-kB. These observations point out to the unique therapeutic potential of this naturally occurring compound in interfering with the signaling pathways that contribute to the osteo-mimicry of these prostate cancer cells. Our preliminary studies on the C4-2B prostate cancer bone metastasis model system emphasize the fact that there are several common denominators between the signaling and function of these metastasizing prostate cancer cells and of osteoblasts/osteoclasts. We believe that curcumin could be a novel inhibitor of these trophisms. Hence, we tested the hypothesis that curcumin inhibits the in vivo development of metastatic osseous foci in either a chemopreventive or therapeutic manner. In particular, curcumin may interfere with the osteomimetic properties of prostate cancer cells or impede common growth factor trophisms. The overall effect would hinder a vicious cycle of co-stimulation within the tumor microenvironment as a result of crosstalk between the invading prostate cancer cells and bone cells. Our results show that curcumin is able to interfere with this cross talk by up-regulating the bone morphogenic protein-7 which is shown to be anti-metastatic [34]. These findings pave the way to a translational approach to inhibit prostate cancer bone metastases in advanced cancer patients in a natural and non-toxic manner.

\section{Materials and Methods}

\subsection{Cell Culture}

C4-2B cells, originally developed by LWK Chung and his co-workers was purchased from ViroMed, Inc, Minnetonka, MN. These cells were maintained in T-medium, as described by these authors, which was supplemented with $5 \%$ heat inactivated fetal bovine serum, $1 \%$ penicillin/streptomycin [31] [32]. The cells were maintained at $37^{\circ} \mathrm{C}$ in $5 \% \mathrm{CO}_{2}$. The cultured cells were certified to be pathogen free by the Radil laboratories at the University of Missouri, St. Louis. The cells were trypsinized using standard procedures, washed with complete medium without antibiotics to remove trypsin and counted using trypan blue for viable cells with a hemacytometer. Immediately after trypsinization and counting, the cells were pelleted by low speed centrifugation and the cell number was adjusted to $2.5 \times 10^{5}$ in a volume of $20 \mu 1$.

\subsection{Curcumin Formulation of the SCID Mice Food}

The commercially available SCID mice diet from Purina, Inc was reformulated to contain $0 \%, 1 \%$ and $2 \%$ curcumin. The source of curcumin used was Sabinsa, Inc (East Windsor, NJ), sold as the C3 complex, which is a purified version of the raw material made up of a majority of diferuloyl methane (93\%) with the reminder being methoxy and bis-dimethoxy diferuloyl methane derivatives. This proprietory blend of curcumin (under US patent \# $5,861,415)$ was used in a synthetic test diet for SCID mice, specially prepared by Purina Test Diets, Inc. The maximum concentration of curcumin in the diet was fixed at $1 \%$ and $2 \%$ on the basis of our preliminary in vivo studies on nude mice using LNCaP cells [25]. These doses were tolerated by mice very well without any untoward toxicity, weight loss or morbidity. The control group of animals were fed with the standard SCID mice diet.

\subsection{Animals}

All procedures were performed with the approval of the Institutional Animal Care and Use Committee (IACUC) of the Hospital for Special Surgery (HSS). Eight week old male Fox Chase SCID mice were obtained from Charles River laboratories (Charles River, Wilmington, MA). Acclimatized animals were castrated to mimic the androgen deprived environment in the advanced and metastatic prostate cancer patient. All the castrated animals were again acclimatized to the new environment for a period of two weeks before beginning the intra tibial tumor cell injections. This timing was necessary for not only allowing the animals to recover from the traumatic surgery but also, more importantly, to allow for their dihydrotestosterone (DHT) levels to fall back to base levels. Animals were randomized into three groups. One group of animals $(n=24,12$ for each $1 \%$ and $2 \%$ curcumin dosing) were injected with the cancer cells and were considerd the "preventive mode". In this group, curcumin dosings were provided in the mice food at the designated levels on the day the tumor cells were injected. In another group of animals ( $\mathrm{n}=24,12$ for each curcumin dosing) in the "therapy" mode, the cancer cells were injected intra-tibially and the lesions were allowed to establish first for a period of two months before the $1 \%$ and $2 \%$ curcumin dosings were started. This situation is designed to simulate the scenario where the prostate cancer patient has bone metastatic lesions established already before any therapy is initiated. The control group of 12 animals received the cancer cells intra-tibially and were maintained on the standard SCID mice diet ( $0 \%$ curcu- 
min). Institutionally approved SOPs were used for all surgery, anesthesia and post-operative care of the animals.

\subsection{Intra-Tibial Injections}

This was done by following the established procedures of Corey et al. [35] and 250,000 C4-2B prostate cancer cells were injected in a total volume of $20 \mu \mathrm{l}$ within 20 minutes of trypsinization of cells. All intra-bone injections were performed under anesthesia using the approved ketamine/xylazine cocktail. Briefly, a 26 gauge needle was inserted 2 to $3 \mathrm{~mm}$ into the proximal end of the tibia using a drilling motion, until the bony resistance is overcome. After injecting the cancer cells in their rich medium, the needle was left in place for 30 more seconds for the interstitial pressure to redistribute and adjust. This was done as a measure to prevent leaking of the injected tumor cells. After this step, the wound was sutured according to the established procedures. Postoperatively, all animals received buprenorphine every 12 hours (for a 24 hour period after the intra-tibial injection) as an analgesic. After an initial period of 2 weeks, the animals were monitored daily for tumor occurrence and burden. In our hands, the C4-2B cells grew slowly under these conditions (but with a 90\% take rate) and a palpable tumor growth was achieved 8 weeks post cell injection.

\subsection{X-Ray Analysis}

For the analysis of the bone metastatic lesions in vivo, mice were anesthetized at end point before sacrifice and examined by flat plate radiography using a digital Faxitron X-Ray instrument (MX-20, Faxitron X-Ray Corp, Wheeling, IL). After X-Ray, the animals were sacrificed humanely according to the established procedures at the HSS. The tumor bearing tibiae and the contralateral tibiae were harvested. Samples were divided for immunohistochemistry and histomorphometric analyses.

\subsection{Histomorphometry}

The harvested tibiae (including the control contralateral tibiae) were fixed with $10 \%$ neutral buffered formalin at $4^{\circ} \mathrm{C}$ for 24 hrs, dehydrated with a graded ethanol series, infiltrated with methyl methacrylate and polymerized at $-20^{\circ} \mathrm{C}$ for three days. Six microns thick longitudinal sections were collected and stained with Goldner trichrome stain and von Kossa stain for histomorphology of the calcified tissue sections. Quantitative histomorphometric analysis was performed on a tissue area confined by the base of the growth plate and the two adjacent cortical endosteal surfaces. Analysis consisted of percentage area occupied by primary and secondary trabeculae relative to the entire tissue surface area occupied within the growth plate/endosteal surface perimeter. The histomorphometry was performed on the Bioquant Osteo II system (Bioquant Inc, Nashville, TN). The data were presented as the percentage of bone volume within total tissue volume in the selected area.

\subsection{Immunohistochemistry}

The harvested tibiae were fixed in 10\% neutral buffered formalin for 48 hours, cleared from the surrounding soft tissue and were decalcified in 10\% EDTA for two weeks. These decalcified tissues were processed, embedded in paraffin and sectioned at five micron thickness. They were routinely stained with with H\&E and safran O for histology. For immunohistochemical analysis, the sections were treated with citrate buffer $(\mathrm{pH}$ 6.0) as an antigen retrieval system using a pressure cooker (Vector Labs, Burlingame, CA) The entire immunohistochemical analyses were performed with the reagents supplied in the Vector-ABC immunoperoxidase labeling system with diaminobenzidine (DAB), using the procedures supplied by the manufacturer. All sections were counterstained with hematoxylin and eosin using the QS solution supplied, cleared and mounted using the non-aquous Vecta-Mount medium. The antibodies used were against 1) Bone morphogenic protein-2; 2) bone morphogenic protein-7; 3) transforming growth factor $\beta$-1; 4) E-Cadherin; 5) prostate specific antigen (PSA); 6) RANK-L; 7) phospho-SMAD1,5,8 and 8) Uncoupling protein-1 (UCP-1). The antibodies 1 through 6 were from R and D Systems, Inc (Minneapolis, MN) and the antibodies 7 and 8 were from Santa Cruz Biotechnologies, Inc, (Dallas, TX). The dilutions tried ranged from 1:100 to 1:200, to arrive at an optimal signal strength. Histochemical examination of tartrate resistant acid phosphatase (TRAP) as a marker for osteoclasts was accomplished using paraffin sections treated with $0.2 \mathrm{M}$ Tris-HCl buffer $\mathrm{pH} 9.4$ and $1 \mathrm{M}$ sodium acetate buffer $\mathrm{pH} 5.0$ prior to the enzyme staining procedure. This activation of enzyme activity and the TRAP staining method is described in Liu et al. [36]. 


\subsection{Statistical Analyses}

Power analyses were performed for the required number of animals to get statistically significant information, given the take rate of C4-2B cells in this experimental system is around $90 \%$ and we achieved that percentage in our hands. Numerical data, particularly those of the histomorphometric analyses were expressed as means $+/-$ standard error of the mean (SEM) Statistical differences between means for various groups were evaluated by the Prism software (Graph Pad) using the ANOVA feature with a level of significance at a p value of $<0.05$.

\section{Results}

The take rates of C4-2B cells and establishment of tumors in bone were found to be $90 \%$ for both the prevention group and the therapy group. The general framework of the animal protocol in the preventive as well as the therapy modes is shown in Figure 1. Curcumin dosings used were $0 \%, 1 \%$ and $2 \%$. The results presented in the following figures and table represent the information obtained in the "therapy" mode. In our hands, the results of the "prevention" mode were characteristically similar to the "therapy" mode.

Figure 2 shows representative images obtained from Faxitron X-Ray imaging. Panel A shows 4 typical tumor bearing tibiae in control ( $0 \%$ Curcumin in diet) animals. Significant osteosclerotic pattern in the cancer cell injected area of the tibiae is seen. However, there was also extensive soft tissue participation and abnormalities. Panel B shows representative tibiae obtained from the animals treated with the 1\% curcumin diet, either in the preventive mode (top 3 specimens) or in the therapy mode (bottom 3 specimens). The overall radiographic pattern differences between the two groups is very minimal. But there was a significant reduction in the osteosclerotic nature of the metastatic lesion as well as soft tissue participation. Panel $\mathrm{C}$ shows the radiographic pattern obtained from tibiae in the $2 \%$ curcumin diet treated animals, with the top three specimens from the preventive mode and the bottom three specimens showing the therapy mode. Note the marked reduction in the extent of tumor progression as well as the metastatic lesions in both modes showing a near-normal pattern with no evidence of osteosclerotic changes and soft tissue involvement.

Table 1 represents the histomorphometric analyses performed on the harvested contralateral tibiae (control) and the test tibiae (from $0 \%, 1 \%$ and $2 \%$ curcumin fed animals) in the therapy mode. The areas proximal to the growth plate and the site of injection were avoided for this analysis and hence, it is very likely that the changes in the bone parameters seen are the result of the growth of prostate cancer cells in the bony microenvironment and not due to the mechanical injury inflicted, which is inherent in this procedure. Histomorphometric determinations of Bone volume (BV), tissue volume (TV) in a given tumor volume adjacent to the growth plate were measured and the results were expressed as the percentages of the ratio of BV to TV. Tumor volume was not measured because the entire tumor was too large. But, the size of the tumors under the three conditions $(0 \%, 1 \%$ and $2 \%$ curcumin in the diet) could be grossly discerned from the Faxitron images. These histomorphometric analyses reveal that when the percentages of the ratio of bone volume to tissue volume was calculated, these

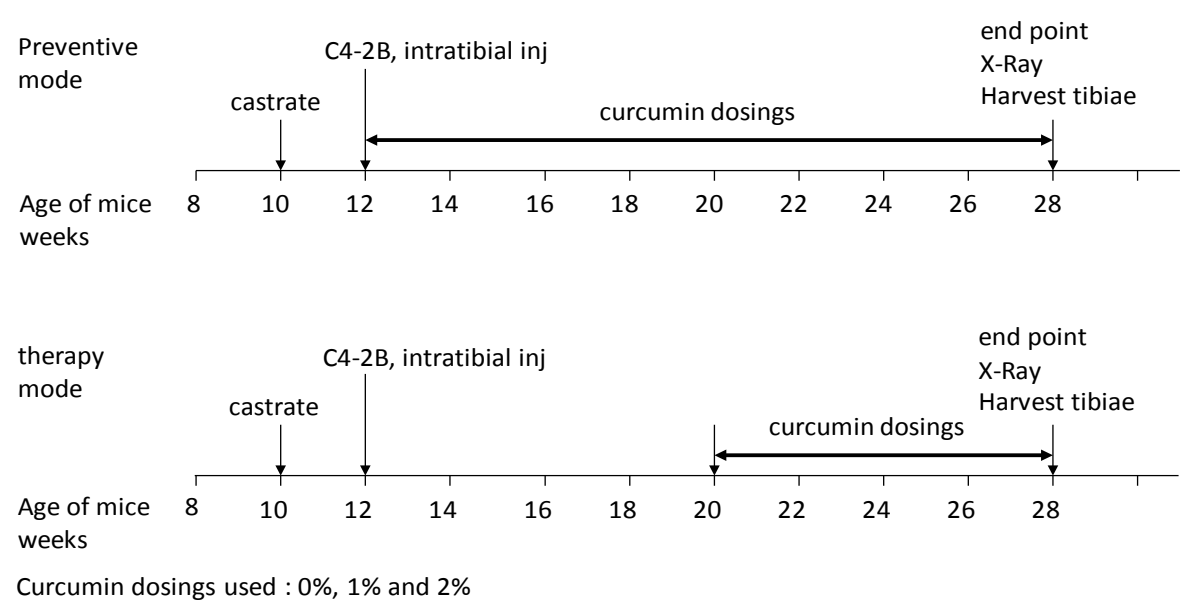

Figure 1. The general framework of the animal protocol in the preventive as well as the therapy modes. Curcumin dosings used were $0 \%, 1 \%$ and $2 \%$. See Materials and Methods for experimental details. 
A

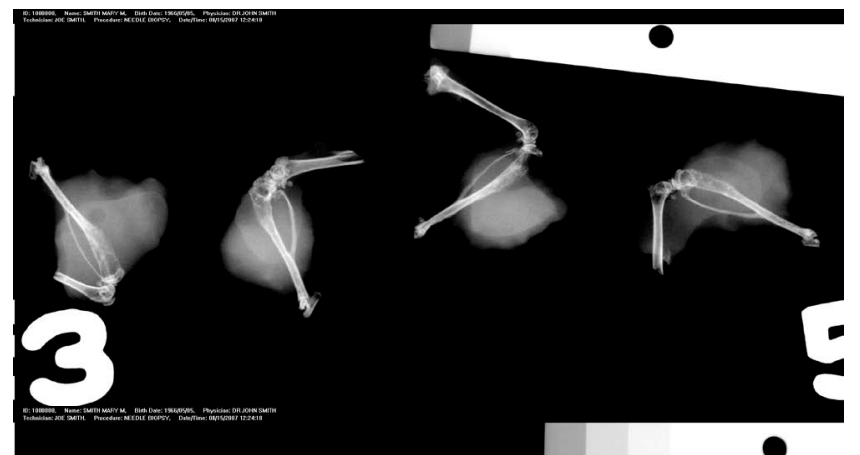

B

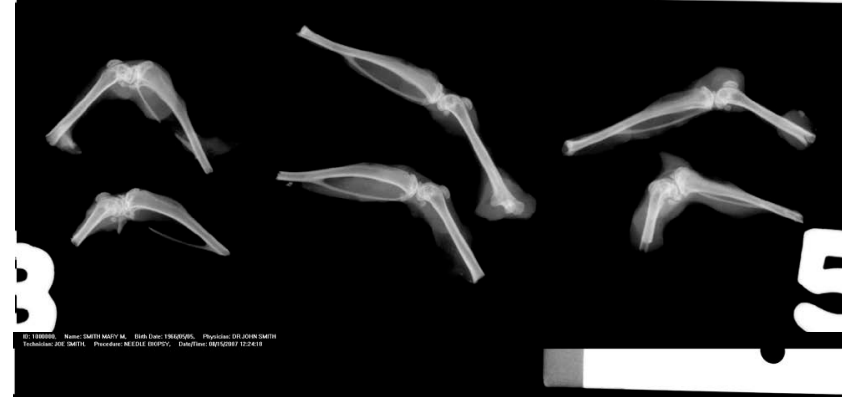

C

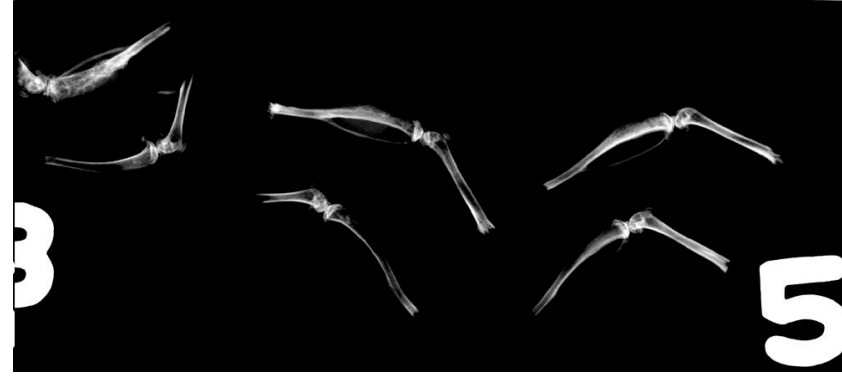

Figure 2. Representative images obtained from Faxitron X-ray imaging. Panel A shows 4 typical tumor bearing tibiae in control $(0 \%$ Curcumin in diet) animals. Significant osteosclerotic pattern in the cancer cell injected area of the tibiae are shown. However, there was also extensive soft tissue invasion and participation. Panel B shows representative tibiae obtained from the animals treated with the $1 \%$ curcumin diet, either in the preventive mode (top 3 specimens) or in the therapy mode (bottom 3 specimens). The overall radiographic pattern differences between the two groups is very similar. There was a significant reduction in the osteosclerotic nature of the metastatic lesion as well as the soft tissue participation as the curcumin dosing increases. Panel $\mathrm{C}$ shows the radiographic pattern obtained from tibiae in the $2 \%$ curcumin diet treated animals, with the top three specimens from the preventive mode and the bottom three specimens showing the therapy mode. The results presented in the following figures and table represent the information obtained in the "therapy" mode. Note the marked reduction in the extent of tumor progression as well as the metastatic lesions in both modes showing a near-normal pattern with no evidence of osteosclerotic changes and soft tissue involvement.

values were nearly constant in the three control groups, but only approached the control/normal value in the $2 \%$ curcumin group. These analyses also revealed that there was a loss of trabecular bone in the $0 \%$ and $1 \%$ curcumintreated animals. Since all the controls had the same amount of trabecular bone, the loss of trabeculae during tumor growth has to be due to the resorption of the trabeculae. These analyses revealed that there is a return to near normalcy in $2 \%$ curcumin treated animals, with respect to the histomorphometric parameters.

Figure 3 represents Representative light microscopic analyses (at $4 \times$ magnification) done on the tumor samples. 
Table 1. Histomorphometric analyses on the bone specimens: The control contralateral tibiae which were not used for cell injection were used in the controls. Histomorphometric determinations of Bone Volume (BV), Tissue Volume (TV) in a given tumor volume adjacent to the growth plate were calculated and the results were expressed as the percentages of the ratio of BV to TV. $0 \%$ control = control tibia with the $0 \%$ curcumin diet; $0 \%$ tumor = test tumor obtained with $0 \%$ curcumin in diet. Similar notations apply to $1 \%$ curcumin and $2 \%$ curcumin feedings. Statistical analyses were performed as described in the Methods section. See Results for an interpretation of the findings.

\begin{tabular}{|c|c|}
\hline \multicolumn{2}{|c|}{ Bone volume/tissue volume (BV/TV) ${ }^{*}$} \\
\hline$\%$ Diet (Curcumin) & BoneVolume/Tissue Volume (\%) \\
\hline 0\% Control & $34.2 \pm 10.2$ (a) \\
\hline $0 \%$ Tumor & $18.4 \pm 11.4$ \\
\hline $1 \%$ Control & $32.3 \pm 9.9$ (b) \\
\hline $1 \%$ Tumor & $18.8 \pm 11.6$ \\
\hline $2 \%$ Control & $37.5 \pm 8.3(\mathrm{c})$ \\
\hline $2 \%$ Tumor & $26.0 \pm 5.7(\mathrm{~d})$ \\
\hline
\end{tabular}

(a): \pm Standard Deviation; (b): $p=0.015$ significance between control and tumor; (c): $p=0.0015$ significance between control and tumor; (d): $\mathrm{p}=0.056$ significance between $1 \%$ Diet and $2 \%$ Diet for BV/TV Tumor; ${ }^{*} \mathrm{BV} / \mathrm{TV}$ is expressed as a percentage.

\section{H\&E 0\% Cur}

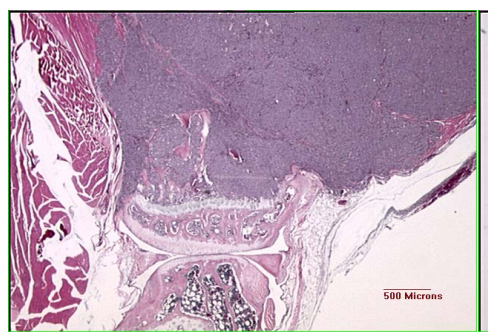

PSA 0\% Cur

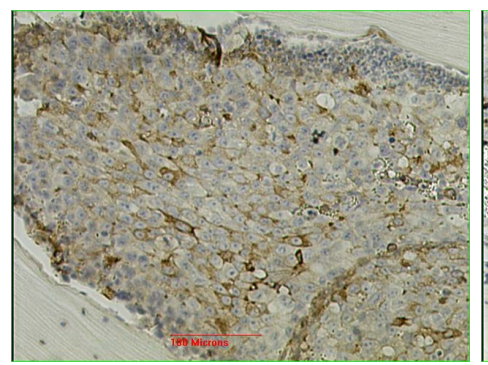

H\&E 1\% Cur

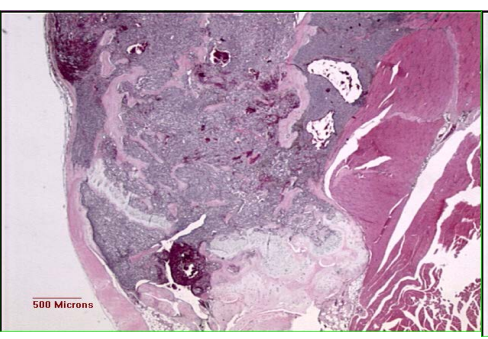

PSA $1 \%$ Cur

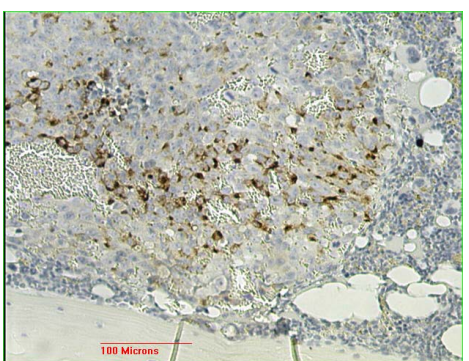

H\&E 2\% Cur

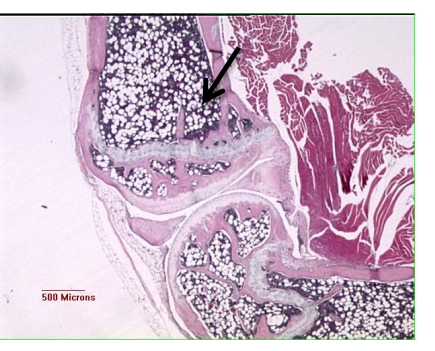

PSA 2\%Cur

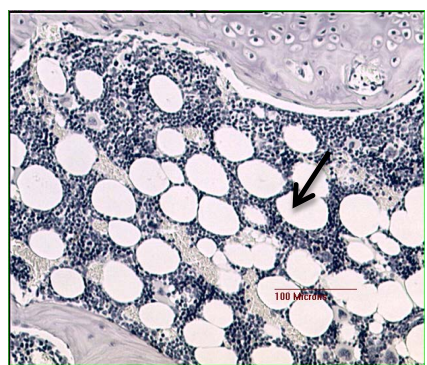

Figure 3. Representative light microscopic analyses done on the tumor samples. The top panel represent the bone sections stained with $\mathrm{H} \& \mathrm{E}$. The $0 \%$ Cur ( $0 \%$ curcumin in diet) shows stained tibia with a very large tumor mass which has not invaded the cartilaginous growth plate. The bone section with $1 \%$ curcumin containing diet shows the tibia that contains a mix of tumor and a few bone marrow cells confined within the cortical bone and the growth plate and the tumor growth is not as intense as in the $0 \%$ cur panel Remarkably, the section of the bone harvested from an animal receiving $2 \%$ curcumin containing diet shows no tumor growth in the tibia. A fatty marrow is seen in both bones (tibia and femur) as well as a normal bone structure (indicated by arrow). The bottom panels show the immunostaining for the presence of prostate specific antigen (PSA) positive cells. This panel shows the decreased staining for PSA as the curcumin in the diet increases. In the left panel ( $0 \%$ curcumin in diet), within the tumor, strong staining is seen in the tumor cell population. The nuclei of the tumor cells are counterstained light blue. In the middle panel, which represents the $1 \%$ curcumin in the diet, the PSA staining was not as marked as in the $0 \%$ cur panel and also not completely eliminated. In the right panel ( $2 \%$ curcumin in diet), there is virtually no stain for PSA and the counterstain highlights the presence of extensive fatty marrow cells (adipocytes with a fatty globular structure). 
The top panel shows the bone sections stained with hematoxylin and eosin (H\&E). The $0 \%$ curcumin ( $0 \%$ curcumin in diet) shows stained tibia with a very large tumor mass which has not invaded the cartilaginous growth plate. The bone section with $1 \%$ curcumin containing diet shows the tibia that contains a mix of tumor and a few bone marrow cells and the tumor growth is not as extensive as in the $0 \%$ curcumin panel. Remarkably, the section of the bone harvested from an animal receiving $2 \%$ curcumin containing diet shows no tumor growth in the tibia. A fatty marrow is seen in both bones (tibia and femur) as well as a normal bone structure. The bottom panels show the immunostaining for the presence of prostate specific antigen (PSA) positive cells. These panels shows the decreased staining for PSA as the curcumin in the diet increases. In the left panel ( $0 \%$ curcumin in diet), within the tumor, strong PSA staining is seen in the tumor cell population. The nuclei of the tumor cells are counterstained light blue. In the middle panel, which represents the $1 \%$ curcumin in the diet, the PSA staining was not as marked as in the $0 \%$ curcumin panel and also not completely eliminated. In the right panel (2\% curcumin in diet), there is virtually no stain for PSA and the counterstain highlights the presence of extensive fatty marrow cells. Nuclei of the fat cells are visible but the cytoplasmic deposits of lipid were dissolved out during tissue processing, leaving empty, round circles mixed between marrow cells. The dramatic decrease in the PSA levels was also corroborated by the analysis of PSA levels in serum prepared at end point through the retro-orbital plexus puncture (data not shown). These results highly suggest that curcumin treatment dramatically induces either a trans-differentiation of tumor cells into adipocytes or a marked proliferation of the bone marrow derived mesenchymal stem cells after receiving a differentiation cue (see below).

Figure 4 represents the immunostaining pattern for RANKL (osteoblast marker) and is strongest at the bone cell-tumor cell junction in this example where the staining was done on a bone section for $0 \%$ curcumin containing diet (top left panel). In the top middle panel (1\% cur in diet), the presence of RANKL was not as strong. Whereas, in the top right panel (2\% curcumin feeding), the RANKL staining is further attenuated. Remarkably, the extensive fatty globules (in adipocytes) were seen in this group of animals (top right panel), indicating the

RANK-L 0\% Cur

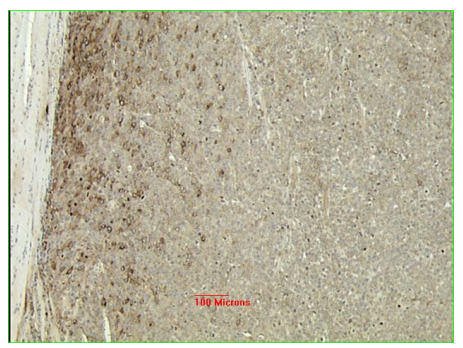

TRAP 0\% Cur

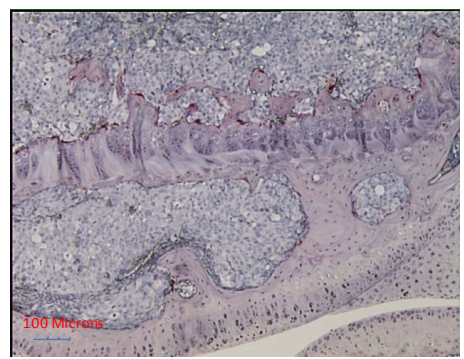

RANK-L 1\% Cur

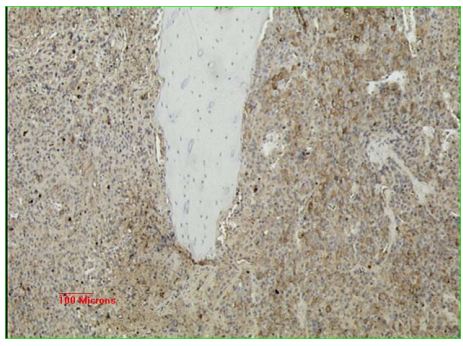

TRAP $1 \%$ Cur

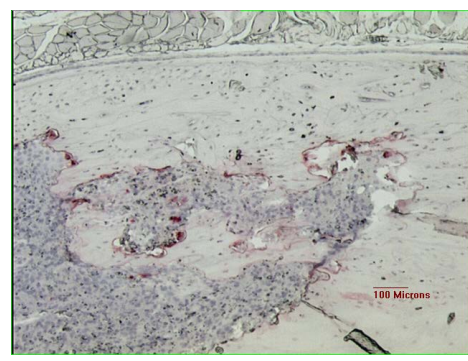

RANK-L 2\% Cur

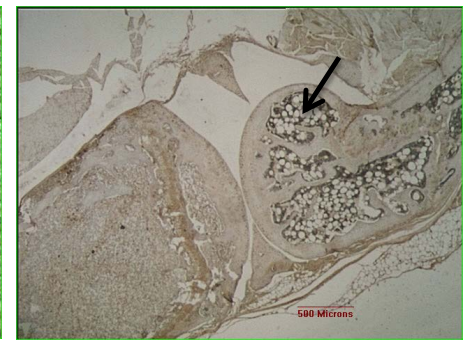

TRAP 2\% Cur

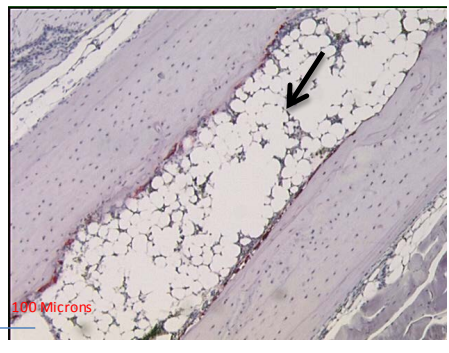

Figure 4. The immunostaining pattern for RANKL (osteoblast marker) appears strongest at the bone celltumor cell junction in this example where the staining was done on a bone section for $0 \%$ curcumin containing diet (top left panel). In the top middle panel (1\% cur in diet), the presence of RANKL was not as strong. Whereas, in the top right panel (2\% curcumin feeding), the RANKL staining is further attenuated. Remarkably, the extensive fatty globules (in adipocytes) were seen in this group of animals (top right panel), indicating the stimulation of an adipocyte differentiation program. The bottom panel represents the TRAP staining for the osteoclasts for tibiae specimens after $0 \%$ (bottom left panel), $1 \%$ (bottom, middle panel) and $2 \%$ (bottom right panel) curcumin feeding. The reduction in the numbers of osteoclasts at the tumor bone interface is not very significant. Again, in the $2 \%$ curcumin treated specimen (bottom right panel), the osteoclasts lining the tumor bone interface is still visible, but the adipocytic differentiation is very marked, with the formation of fatty marrow cells, as indicated by arrow. 
stimulation of an adipocyte differentiation program. The bottom panel represents the TRAP staining for the osteoclasts for tibiae specimens after 0\% (bottom left panel), 1\% (bottom, middle panel) and 2\% (bottom right panel) curcumin feeding. The reduction in the numbers of osteoclasts at the tumor bone interface is not very significant. Again, in the $2 \%$ curcumin treated specimen (bottom right panel), the osteoclasts lining the tumor bone interface appear to be attenuated, is still visible. But, the adipocytic differentiation is very marked, with the formation of fatty marrow cells. These results suggest that at these curcumin concentrations, the osteoblasts as well as the osteoclasts are not severely affected but the fatty marrow/globular differentiation within the cancer cell injected areas is significantly up-regulated.

The results obtained so far highly suggested that there was a marked reprogramming of the cell populations in the tumor area, after receiving a particular cue or stimulus as a result of curcumin treatment. Therefore, we reasoned that the TGF- $\beta$ expression pattern in the bone matrix will also be modulated as a result. This prompted us to stain the sections for the level of expression of the native TGF- $\beta 1$ as well as the TGF- $\beta$ family member BMP-2. The results are shown in Figure 5. This figure shows a discernible down regulation of the expression of TGF- $\beta$ and an up-regulation of the bone morphogenic protein BMP-2 as a result of curcumin feeding, as compared to $0 \%$ curcumin fed controls. However, when we performed the immunohistochemical analysis using antibodies specific for phospho SMAD $2 / 3$ as a functional readout of this TGF- $\beta$ /BMP-2 changes, we did not observe any significant changes in the level of expression of pSMAD 2/3 (data not shown). We infer from this negative finding that the downstream signaling that arises from these two proteins was not significantly affected. Curcumin's bone metastasis inhibitory potential on the basis of the radiographic analysis as described in Figure 2 as well as the lack of significant modulation of either TGF- $\beta$ or BMP-2 in these tibiae highly suggested that this naturally occurring compound might target the metastasis inhibitory TGF- $\beta$ family member namely bone morphogenic protein-7 (BMP-7) for up-regulation [34]. Therefore we proceeded to stain the sections for BMP-7, the results of which are described in Figure 6, top panel. The results highly suggest that there is a relative up-regulation of this bone morphogenic protein. As a functional readout for this up-regulation we show the marked up-regulation of the phosphorylation of the SMAD proteins 1, 5, 8 using a pan-specific antibody (Figure 6, bottom panel). Again, one can see in this figure the marked up-regulation of the adipogenic differentiation as the curcumin levels in the diet increases. These results indicate that, relatively, the BMP-7 expression is expressed at a higher level than TGF- $\beta$ in the bone matrix. This also suggested that the differentiation cue that forces a marked adipogenesis in the bone marrow could in fact come from BMP-7. Since BMP-7 functions in-
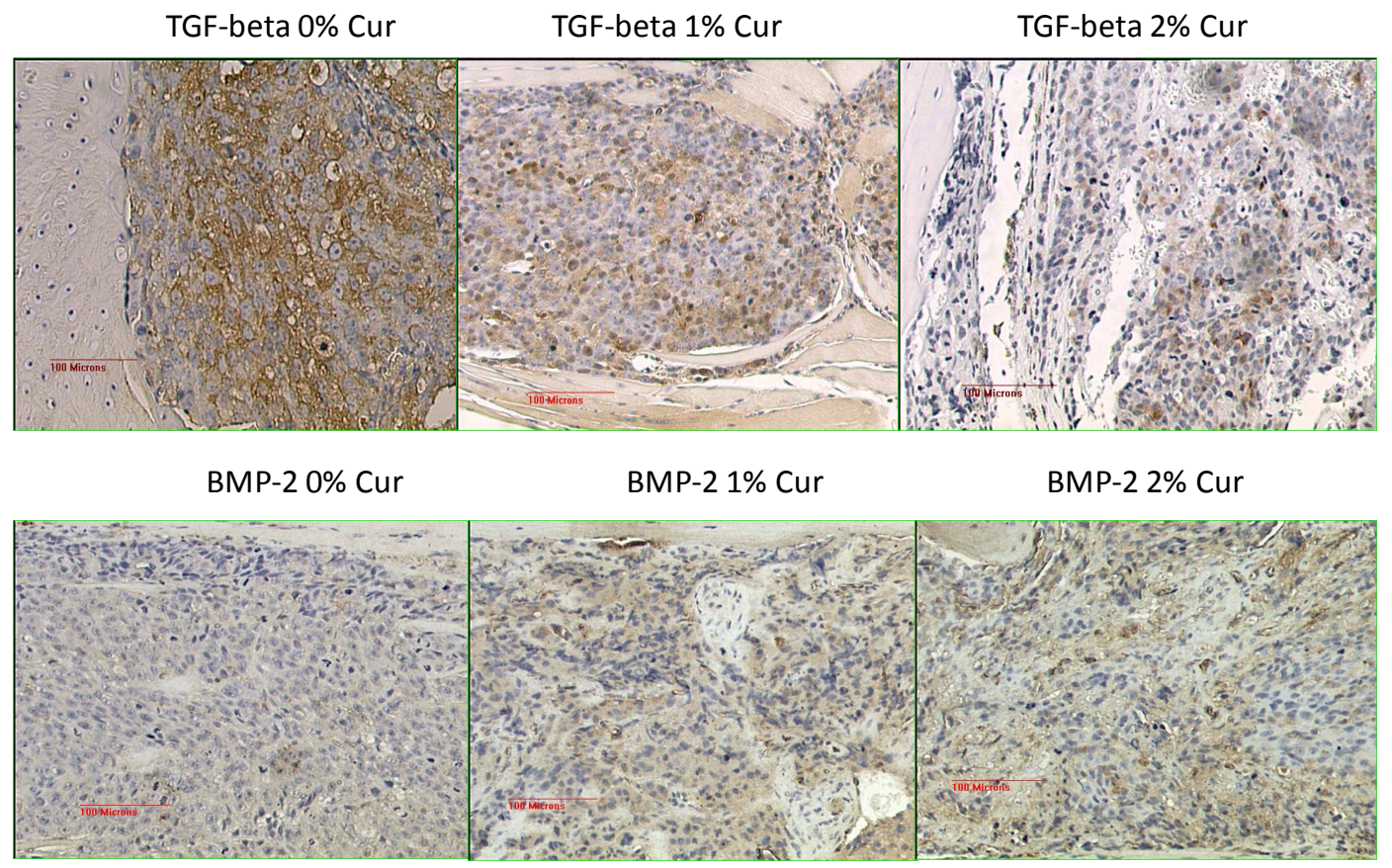

Figure 5. TGF- $\beta 1$ expression levels (top panel) and bone morphogenic protein-2 (BMP-2, bottom panel) levels in the curcumin as well as the control diet fed animals. 
0\% CUR Tumor, BMP-7

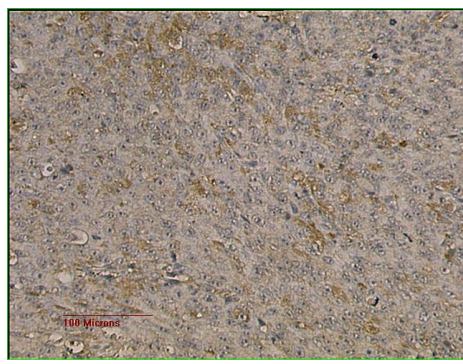

0\% CUR Tumor 4XpSMAD158
1\% CUR Tumor, BMP-7

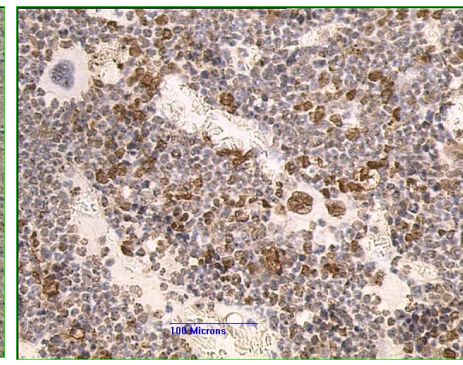

1\% CUR Tumor 4X pSMAD158
2\% CUR Tumor, BMP-7

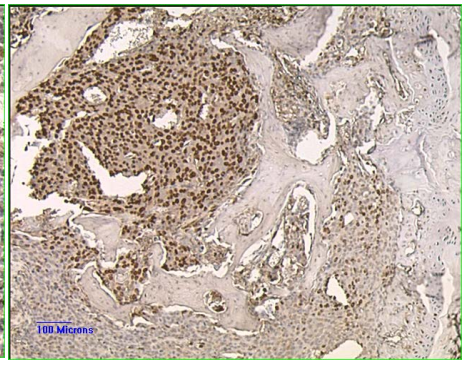

2\% CUR Tumor 4X pSMAD158

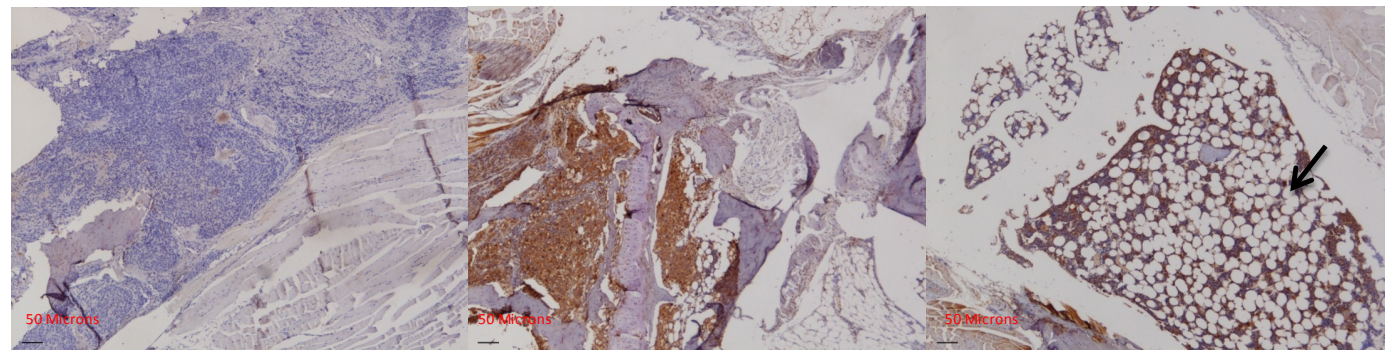

Figure 6. The modulation of bone morphogenic protein-7 (BMP-7) in the control diet as well as $1 \%$ and $2 \%$ curcumin fed animals (top panel). The bottom panel shows the functional readout for BMP-7 expression, namely phosphorylation level of SMAD 1, 5, 8 using a pan-antibody. Note the extensive adipogenic differentiation (indicated by the arrow) within the markedly decreased tumor cell population, as well as an increase in the pSMAD staining levels as the curcumin in the diet increases.

tercellularly to force a mesenchymal to epithelial transition among cells, we looked for the relative level of expression of the EMT marker epithelial cadherin (E-Cadherin). Figure 7 shows a relatively higher level of expression of E-Cadherin as the curcumin dosage in the diet is increased. These results are consistent with the notion that the dramatic effects seen in the bone matrix as a result of curcumin treatment is due to the effects of the up-regulated BMP-7 which could alter the BMP-7/TGF- $\beta$ ratio within the bony microenvironment.

We then wished to determine the nature of the adipogenic differentiation that is seen in our work. This is particularly puzzling because of the known effects of curcumin in interfering with fat metabolism that results in an overall reduction in adiposity in vitro and in vivo as shown by other investigators. This prompted us to suspect that whether curcumin's overall anti-adipogenic effects could be microenvironment and/or context dependent. Based on the differentiation cues that are altered by curcumin (in our case, namely BMP-7), we reasoned that curcumin, in the context of a microenvironment which is biased in favor of an up-regulated BMP-7 would in fact favor a special type of adipogenic differentiation other than the classical (and often seen) white adipogenic tissue (WAT) genesis. Since BMP-7 is already known to induce brown adipose tissue (BAT) formation, we wished to look for this type of fat cell differentiation in our bone specimens. The classical Oil Red-O stain in these sections could not be done here since all the specimens obtained were paraffin fixed. This stain, on its own merit, would not have distinguished whether the fat cells seen here are coming from white adipose lineage or the brown adipose lineage. Therefore, we took a different route for these analyses and began looking for a marker protein which is specific for the brown or beige adipocyte cell lineage, namely the mitochondrial uncoupling protein-1 (UCP-1) which is responsible for the adaptive thermogenesis in these special cells [37]. Figure 8 shows the marked up-regulation of the UCP-1 stain in the bone marrow as the curcumin levels in the diet increases. The top panel shows the up-regulation of UCP- 1 a lower magnification (4×) while the bottom panel shows the same results at a higher $(20 \times)$ magnification. The diaminobenzidine based brown stain is indeed very marked at the cellular membrane boundaries of the fat cells and they appear to leach out of the cells, as a result of the loss of lipid content during the deparaffinization process. Therefore, it is very likely that, within the parameters of the experimental conditions used, the UCP-1 protein is preserved at the defatted membrane boundaries, as shown by the arrows in Figure 8 .

Figure 9 diagrammatically shows a summary of the conclusions reached in this work. Curcumin treatment 

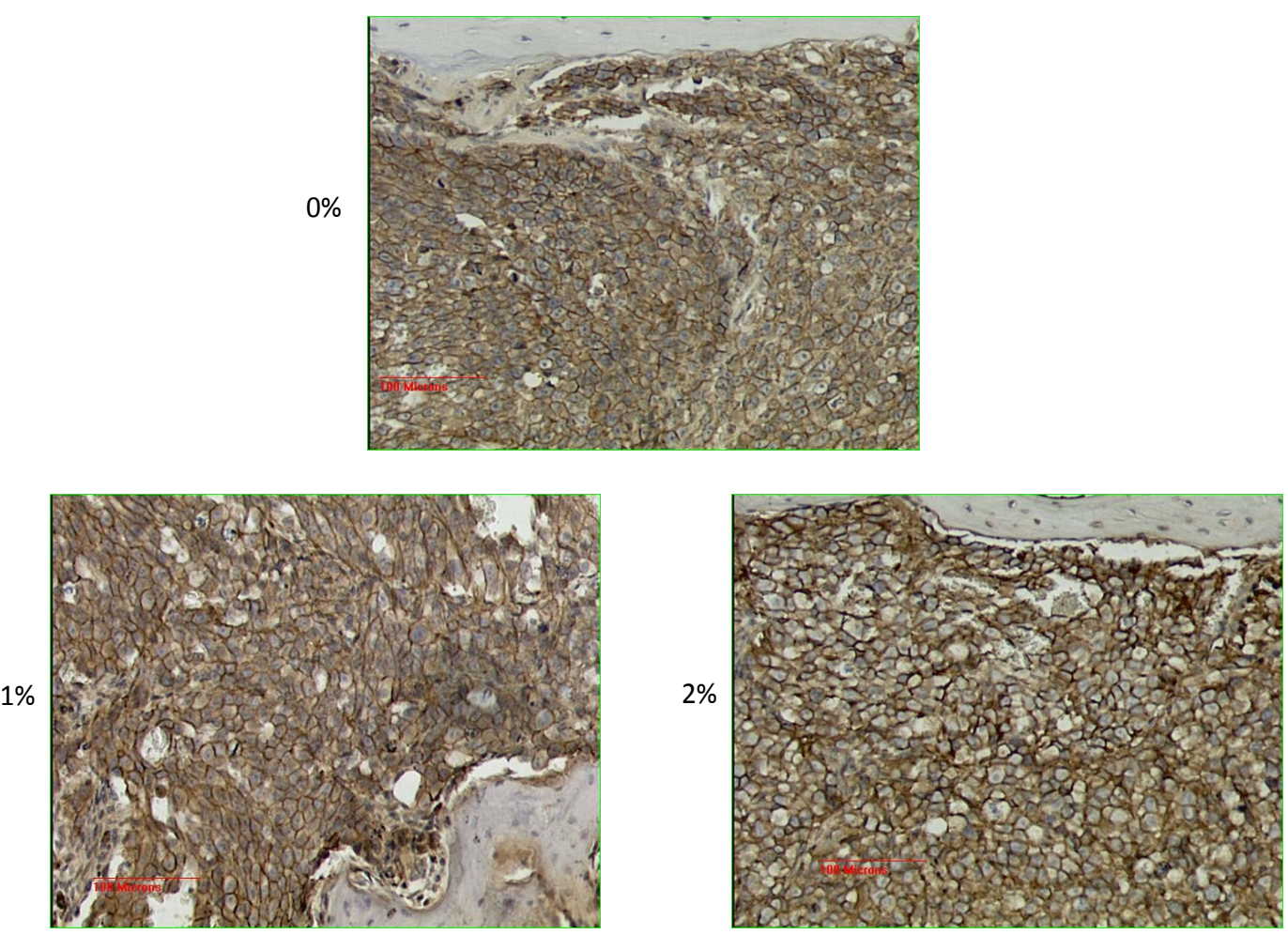

Figure 7. E-Cadherin expression as a measure of the level of epithelial-mesenchymal transition that takes place as a result of BMP-7 up-regulation in the control diet ( $0 \%$ cur) as well as $1 \%$ and $2 \%$ curcumin diet treated animals.

\section{0\% CUR Tumor 4X, UCP-1}

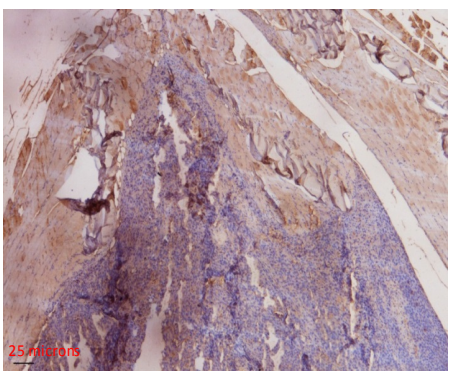

1\% CUR Tumor 4X, UCP-1

2\% CUR Tumor 4X, UCP-1
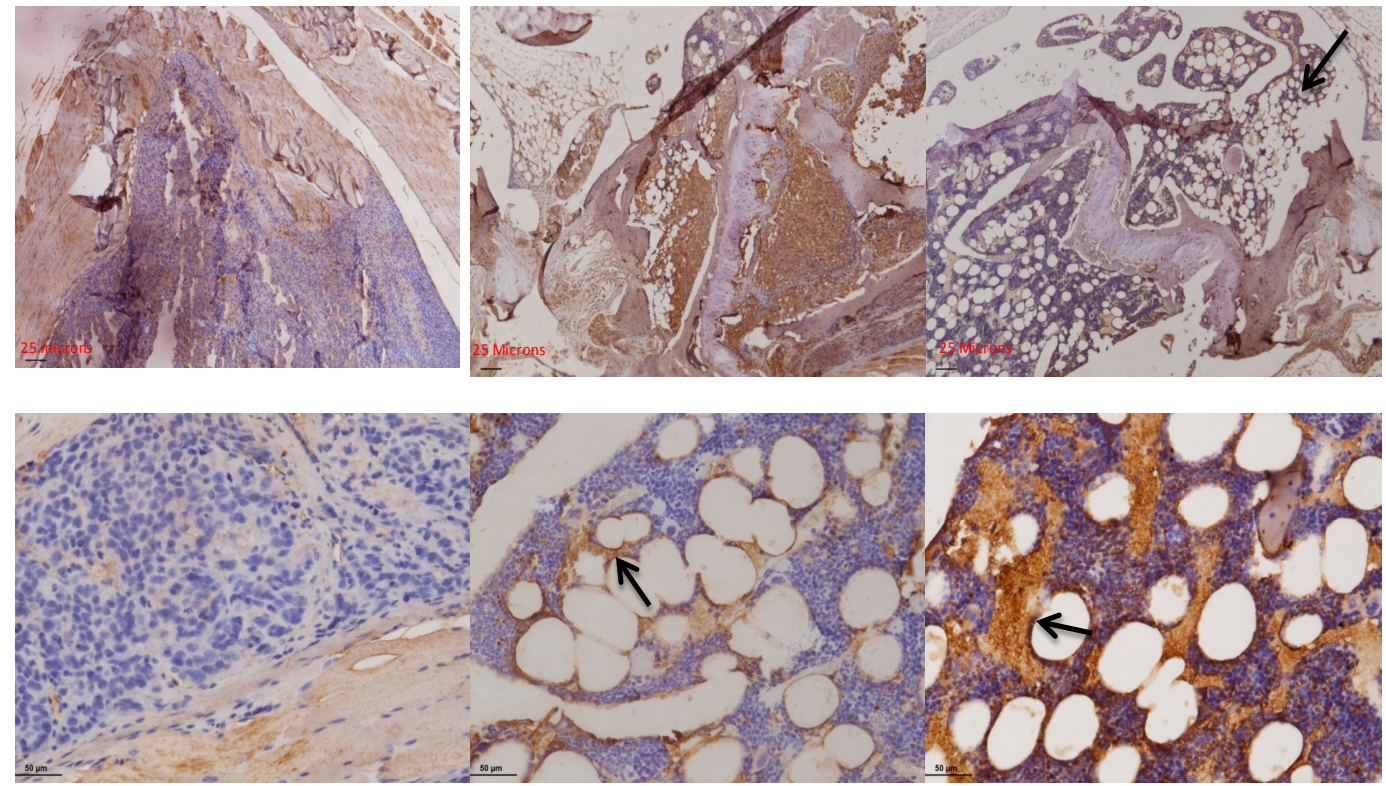

Figure 8. The brown fat nature of the adipocytes seen in this work as a result of curcumin feeding. The top panel shows the level of the expression of the mitochondrial uncoupling protein UCP-1 at low magnification $(4 \times)$ in $0 \%$ curcumin (control diet) as well as $1 \%$ and $2 \%$ curcumin treated animals. The bottom panel shows the same information at a higher magnification $(20 \times)$. Arrows indicate that the brown stain is arising from the fat cells, as the periphery is stained. 


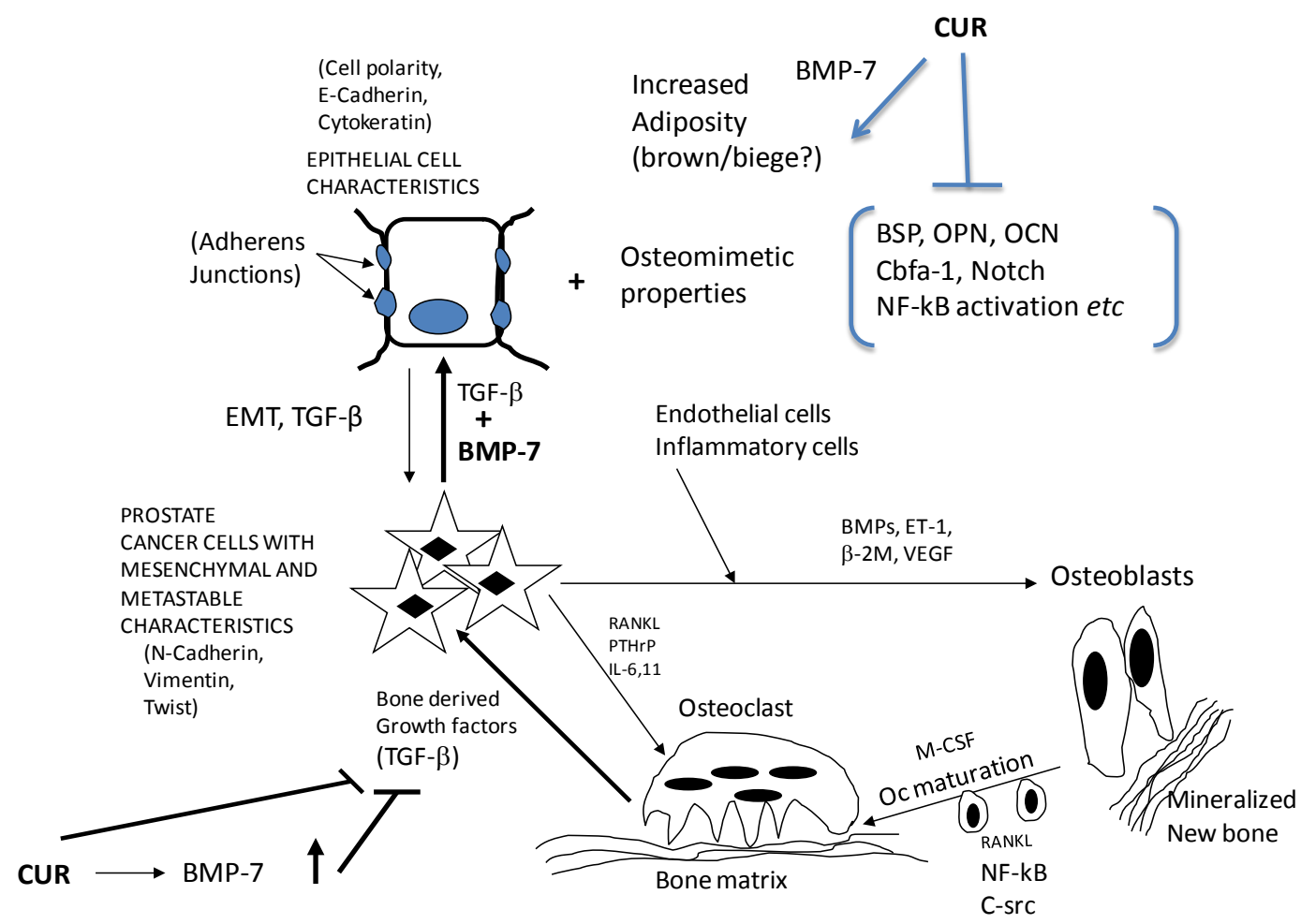

\begin{abstract}
Figure 9. A summary of the conclusions reached in this work. Curcumin treatment up-regulates the expression of BMP-7 either in the prostate cancer cells themselves or in the bone marrow derived mesenchymal stem cells which seem to have a negative regulatory effect on the cancer progression as seen in the near normal X-Rays after treatment. The up-regulation of BMP-7 may alter the BMP-7/TGF- $\beta$ ratio to tip it towards a more mesenchymal-to-epithelial transition (MET). The expressed osteomimetic properties are inhibited by curcumin as shown in our previous work. At the same time, the up-regulated BMP-7 induces an adipogenic differentiation program characteristic of either the brown fat or the beige fat lineage. The ultimate result of all these processes is that there may be a distinct brake on the vicious feed forward cycle of reciprocal activation of osteoclasts and more TGF- $\beta$ release from osteoclasts. See Discussion for details.
\end{abstract}

very likely up-regulates the expression of BMP-7 either in the prostate cancer cells themselves or in the bone marrow derived mesenchymal stem cells which seem to have a negative regulatory effect on the cancer progression as seen in the near normal X-Rays after treatment. The up-regulation of BMP-7 may alter the BMP-7/ TGF- $\beta$ ratio to tip it towards a more mesenchymal-to-epithelial transition (MET). The expressed osteomimetic properties are inhibited by curcumin. At the same time, the up-regulated BMP-7 induces an adipogenic differentiation, characteristic of either the brown fat or the beige fat lineage both of which exhibit the expression of the protein UCP-1. The ultimate result of all these processes is that there is a distinct drive to inhibit the vicious feed forward cycle of reciprocal activation of osteoclasts and more TGF- $\beta$ release from the bone matrix.

Even though the curcumin dosings administered in this study were selected on the basis of our earlier work on the effects of this naturally occurring compound in prostate cancer bearing nude mice (to prevent undue apoptosis), we cannot completely rule out the possibility that some of the results described in this work could arise from a direct effect of curcumin on the proliferation of these C4-2B cells [25].

\title{
4. Discussion
}

Our results highlight the importance of using this dietary ingredient curcumin in either preventing the establishment of or in treating the established bone metastases in an animal model system. In the bone microenvironment, prostate cancer cells interact with the bone cells using the mechanisms of osteotrophisms described above and disrupt the normal processes of bone remodeling, causing either osteoblastic, osteoclastic or osteosclerotic metastases. The rich stores of growth factors saved in the mineralized bone matrix such as transforming growth factor- $\beta$ (TGF- $\beta$ ) are released during the bone destruction process. The cancer cells feed on these growth factors 
and secrete more osteolytic factors such as PTHrP, IL-6 and IL-11 which in turn further stimulate osteoclastic resorption and increase TGF- $\beta$ release. Thus, TGF- $\beta$ plays a central role in this vicious cycle of bone metastasis and hence, the TGF- $\beta$ signaling pathway in tumor cells and its cross talk within the bone microenvironment present as attractive therapeutic targets [38]-[41]. Very recently, Buijs and coworkers demonstrated that, in prostate cancer cells, a member of the TGF- $\beta$ ligand family, called the bone morphogenic protein-7 (BMP-7) is an antagonist of the TGF- $\beta$ signaling pathway and can inhibit osteolytic metastases that are attributable to prostate cancer in vivo [34] [42]-[45]. These workers have shown that while TGF- $\beta$ alone decreases E-Cadherin expression and creates the epithelial mesenchymal transition (EMT) in prostate cancer cells which portends the invasive and metastatic phenotype, a combination of TGF- $\beta$ and BMP-7 have just the opposite effect in enhancing E-Cadherin expression and promoting the epithelial phenotype and inhibiting the development of prostate cancer bone metastases [34]. Secondly, these workers established the concept that BMP-7 exhibits its anti-metastatic properties in the context of TGF- $\beta$, rather than either growth factor acting alone. Thus, BMP-7 could be used as a TGF- $\beta$ antagonist in the treatment of osteolytic as well as osteoblastic metastases arising from prostate cancer. The most important finding in the studies performed here is that curcumin is able to enhance BMP-7 expression in the presence of TGF- $\beta$ so as to compete with the canonical TGF- $\beta$ signaling within the bone matrix and bring up the inhibitory effect on the metastatic process. The fact that in $2 \%$ curcumin treated animals, the entire injected area in the tibiae were replaced by fatty marrow cells with very few tumor cells highly suggest that an alteration in the balance of TGF- $\beta$ signaling brought up by BMP-7 could be the reason for the inhibition of bone metastatic lesions seen in this study.

Loss of BMP-7 expression by the cancer cells and/or resistance of these cells to the BMP-7 secreted by the surrounding normal epithelial or stromal cells forces the malignant cells to function with a TGF- $\beta$ bias (without a check and balance by BMP-7), promoting loss of E-Cadherin expression and metastasis. By the studies described here, we believe that curcumin is able to reprogram the check and balance of the signaling pathways mediated by TGF- $\beta$ by up-regulating the expression of BMP-7. It is possible that curcumin is able to achieve this by either up-regulating the expression of BMP-7 directly by the cancer cells [46] or by enhancing its expression in the surrounding bone marrow derived stem cells. It is already well known that one of the mechanisms by which curcumin is able to bring up its anti-inflammatory action is by an up-regulation of the peroxisome proliferator activated receptor- $\gamma$ (PPAR- $\gamma$ ) [47] [48]. Since very recent studies indicate that PPAR- $\gamma$ activation indeed modulates TGF- $\beta$ signaling, it is tempting to hypothesize that one of the plausible mechanisms by which curcumin could mediate its negative effect on TGF- $\beta$ signaling is through the up-regulation of BMP-7 which is brought up by PPAR- $\gamma$ up-regulation. This concept is also supported by the work of Kiss et al. who recently showed that another PPAR- $\gamma$ agonist rosiglitazone suppressed the expression of transforming growth factor- $\beta 1$ (TGF- $\beta 1$ ) while at the same time up-regulated the expression of BMP-7 in a renal allograft model resulting in an inhibition of fibrosis [49]. It is also well known that curcumin is capable of inhibiting the Wnt signaling pathways while at the same time activating the peroxisome proliferator activated receptor- $\gamma$ (PPAR- $\gamma$ ) [50]. Earlier, we have shown that curcumin is capable of interfering with the osteomimetic properties exhibited by the C4-2B prostate cancer cells that enable them to be hosted by the osteoblasts as well as the osteoclasts in the bony microenvironment [26]. And, by activating the PPAR- $\gamma$ pathway, it may also be capable of inhibiting the cross-talk that occurs between the signaling pathways devoted to bone morphogenic proteins and TGF- $\beta$ [51].

Consumption of curcumin is known to reduce obesity as evidenced by lower fat mass and increased fat utilization. In parallel, curcumin reduces the expression of pro-inflammatory adipokines, tumor necrosis factor- $\alpha$ (TNF- $\alpha$ ), monocyte chemoattractant protein (MCP-1) while at the same time inducing the expression of adiponectin which is a principal anti-inflammatory agent secreted by the adipocytes [52]-[56]. All these beneficial effects of curcumin pertain to the direct effect of this naturally occurring compound in interfering with the adipocyte differentiation and in the promotion of its anti-oxidant activities. Therefore, we believe that the increase in a type of adipocytes (in the fatty marrow seen in our work after curcumin feeding) in the bony metastatic lesions very likely represents a unique effect of curcumin in the bony microenvironment, particularly in modulating the bone marrow derived mesenchymal stem cells (BM-MSCs). These MSCs are multipotent cells which have the ability to give raise to adipocytes and osteoblasts. This bifurcation in the differentiation pathway and the ultimate cell fate is very tightly controlled. Differentiation inducing stimuli that favor one cell fate actively repress mechanisms that induce the other cell lineage. For example, the canonical Wnt/ $\beta$-catenin signaling pathway induces osteoblastogenesis and inhibits adipogenesis while the PPAR- $\gamma$ pathway is a prime inducer of BMP-7 and adipogenesis while suppressing osteoblastogenesis [57]-[61]. Thus, this BMP-7 up-regulation and adipogenesis 
are context dependent, particularly within the bony matrix with a reservoir of TGF- $\beta$. Curcumin appears to alter the delicate balance between osteoblastic and adipogenic differentiation programs and shift this balance towards a special type of adipogenic differentiation. More specifically, our results highly suggest that curcumin up-regulates the expression of BMP-7, a bone morphogenic protein that is known to induce the brown adipose tissue (BAT) adipogenic differentiation program and not the white adipose tissue (WAT) differentiation program. To prove our point, we stained the bone metastatic lesions immunohistochemically for the mitochondrial uncoupling protein-1 (UCP-1) which is a specific marker for BAT [37]. The marked staining of this protein in the metastatic lesions suggest that this BAT differentiation program is indeed activated. But, under the experimental conditions used, we do not yet know whether these brown fat cells are arising from the BM-MSCs taking the cue from BMP-7 or whether they arise from the existing WAT cells using a BMP-7 driven trans-differentiation program to produce beige/brite fat cells which also express UCP-1 or whether certain osteoblasts are forced to undergo this trans-differentiation under the influence of BMP-7 [62]. Whatever the ultimate mechanism is, there is strong evidence on the basis of our studies that the up-regulated BMP-7 is indeed altering the cell fate determination programs within the metastatic lesions (i.e., within the bone marrow). Therefore, we infer that the intricate collaboration between the incoming prostate cancer cells and the osteoblasts and osteoclasts within the bony microenvironment will be affected, resulting in a severely restricted drive to go through the vicious cycle of reciprocal activation and release of osteolytic growth factors in these metastatic lesions.

More recently, Wright et al. addressed the beneficial effects of curcumin in inhibiting the TGF- $\beta$ signaling in human breast cancer cells in vitro and in limiting the osteolysis by the same cells in an in vivo metastatic model system [63]. Their system suggested that curcuminoids prevented the induction of parathyroid hormone related protein (PTHrP), which facilitates the vicious cycle of osteolytic bone destruction by TGF- $\beta$ via blockade of Smad signaling. While their findings are novel and are in line with our overall conclusions, their studies highlight the possible molecular differences between the prostate cancer bone metastatic lesions and breast cancer bone metastatic lesions. Possibly, the expression of the osteomimetic properties (for which the C4-2B prostate cancer cells are well known for), is also different in their breast cancer model system (MDA-MB-231). The fact that they did not observe the remarkable up-regulation of BMP-7 and brown/beige adipose tissue differentiation (as exemplified by UCP-1 up-regulation as seen in our studies) is puzzling. It could be attributed to the differences in the animal systems used, cancer cells used, differences in the levels of hormone refractoriness of these cells, in the sourcing and doses of curcumin. Another issue that was not addressed in the studies by Wright et al. is the antagonistic relationship between TGF- $\beta$ signaling and PPAR- $\gamma$ activation in their experimental system [64]. For example, it is known that disruption of TGF- $\beta$ signaling by curcumin induced gene expression of PPAR- $\gamma$ in rat hepatic stellate cells (HSC) [65]. In this study, treatment with exogeneous TGF- $\beta$ inhibited the gene expression of PPAR- $\gamma$ in activated HSC and this inhibition was relieved by pre-treatment with curcumin, likely by interrupting TGF- $\beta$ signaling. Studies published earlier by Morrissey et al. that were similar to ours focused on the expression levels of BMP-7 on prostate cancer cells in vitro and in the tumor microenvironment in vivo [66]. These authors showed that BMP-7 is expressed at a higher level in metastatic prostate cancer cells (C4-2 cells) compared to androgen dependent LNCaP cells. While BMP-7 inhibited the proliferation of LNCaP cells, stimulated their androgen receptor (AR) mediated signaling and the expression of differentiation associated genes such as prostate specific antigen (PSA) and kallikrein-2, these effects were not observed in C4-2 cells which are androgen independent. Moreover, in vivo expression of BMP-7 in C4-2 cells did not alter their proliferation when these cells were grown in a non-osseous environment but their growth was inhibited when grown in an osseous environment. Their results highly suggested that the growth inhibitory effects of BMP-7 is dependent upon the phenotype and the differentiation status of these prostate cancer cells and the tumor microenvironment. Second, the expression of BMP-7 in androgen dependent prostate cancer and castration resistant prostate cancer may be under different levels of control. As the authors point out, BMP-7 may be regulated by androgens in androgen dependent LNCaP cells and in the naïve prostate. It is very likely that even though BMP-7 is expressed at a higher level in castration resistant C4-2 cells, this morphogenic protein is under the control of factors such as PPAR- $\gamma$ in addition to getting regulated by AR, as shown by other investigators. Third, the authors highlight the "dual" role of BMP-7 in regulating the AR activity by decreasing the association between $\beta$-catenin and AR with a concomitant increase in E-Cadherin expression in androgen dependent LNCaP cells, an effect which was not observed in the castration resistant C4-2 cells. What is evident from their studies is the fact that the cross talk that occurs between the cell signaling pathways (BMP, AR, Wnt $/ \beta$-catenin) is clearly different when the cancer progresses from the androgen dependent to an androgen independent state. 
Therefore, factors, particularly the naturally occurring non-toxic compounds like curcumin which are capable of up-regulating BMP-7 on their own merit (possibly by its established activating effect on PPAR- $\gamma$ pathway and inhibitory effect on the Wnt $/ \beta$-catenin pathway) may in fact bypass these regulatory circuits controlled by AR irrespective of whether the cancer is in its primary (LNCaP) site or in its bone metastatic site (C4-2) gain more significance. As a result, this molecular explanation of how curcumin works in androgen independent human prostate cancer progression system, as exemplified in our C4-2B cell studies reinforces this compound's validation and inclusion in clinical trials.

Our current studies offer a natural, non-toxic and an inexpensive means of up-regulating this metastasis inhibiting growth factor in the bony microenvironment in the context of TGF- $\beta$. We believe that our studies take the effect of BMP-7 (as a result of curcumin feeding) with regards to the inhibition of prostate cancer bone metastasis one step further, namely, the brown fat development in bony metastases and the inhibitory role that they could play in the maintenance and/or functioning of bony metastases [67]. The fact that these tumor bearing animals show near normal radiographs after $2 \%$ dietary curcumin treatment either in the chemoprevention mode or in the therapy mode, with no weight loss or morbidity or toxicity along with the disappearance of bony metastatic lesions compared to controls and with the initiation of a "brown-fat like" differentiation program in the bony metastatic lesion sites highly suggest that BMP-7 can severely restrict the establishment of or inhibit the established metastases in a broader context. These concepts are described diagrammatically in Figure 9.

\section{Conclusion}

In conclusion, we believe first that this naturally occurring compound is ideally suited to alter the cell signaling pathways in the bony metastatic lesions so as to "subvert" the bone cell remodeling processes mediated by the cross talk between the extracellular matrix, osteoblasts and the osteoclasts to an alternative differentiation program, namely the BAT pathway. As a consequence of repurposing these differentiation cues, it is very plausible that the resultant brown fat cell differentiation program may stop the perennial bone destruction and remodeling that occurs in these metastatic lesions. Secondly, on the basis of our results, it is worth considering the use of curcumin in prostate cancer bone metastasis treatment either alone or in an adjuvant setting along with the existing therapies such as nitrogen containing bisphosphonates (N-BPs). It may even be possible to reduce the dose of N-BPs in the presence of curcumin to achieve the same results, thereby reducing the occurrence of posttherapy complications such as osteonecrosis of the jaw (ONJ) [68]. It may also be possible to administer curcumin along with other PPAR- $\gamma$ agonists which are currently in clinical use to up-regulate BMP-7 to achieve a better inhibitory potential. Third, even though curcumin possesses some limitations such as poor bioavailability due to poor absorption, rapid metabolism and excretion of the glucuronidated metabolites, our studies show that a certain (still not well characterized) metabolite of curcumin which may be available in extremely low amounts in the blood stream after curcumin feeding is enough to bring up these remarkable anti-metastatic effects [69]. Finally, there are several emerging strategies that address the treatment of metastatic cancer focusing on "killing the seed or disturbing the soil" [70]. We have reasons to believe that curcumin is capable of doing both at the same time, with the ultimate result of preventing these bone metastatic lesions.

\section{Acknowledgements}

This study was supported by funding from the National Institutes of Health (NIH CA-119189) to TD. The authors gratefully acknowledge the encouragement and support of Bharat B. Aggarwal for this work and the helpful advice by Robert Vessella on how to perfect the intra-tibial technique. TD thanks John T. Pinto for a critical reading of the manuscript.

\section{References}

[1] Denmeade, S.R. and Isaacs, J.T. (2002) A History of Prostate Cancer Treatment. Nature Reviews Cancer, 2, 389-396. http://dx.doi.org/10.1038/nrc801

[2] Isaacs, J.T. (1999) The Biology of Hormone Refractory Prostate Cancer: Why Does It Develop? Urologic Clinics of North America, 26, 263-273. http://dx.doi.org/10.1016/S0094-0143(05)70066-5

[3] Parkin, D.M. and Muir, C.S. (1992) Cancer Incidence in Five Continents. Comparability and Quality of Data. IARC Scientific Publications, 120, 145-173.

[4] Sim, H.G. and Cheng, C.W. (2005) Changing Demography of Prostate Cancer in Asia. European Journal of Cancer, 
41, 834-845. http://dx.doi.org/10.1016/j.ejca.2004.12.033

[5] Greenbee, R.T., Hill-Harmon, M.B., Murray, T. and Thun, M. (2001) Cancer Statistics. CA: A Cancer Journal for Clinicians, 51, 15-36.

[6] Boyle, P., Kevi, R., Lucchuni, F. and La Vecchia, C. (1993) Trends in Diet Related Cancers in Japan: A Conundrum? Lancet, 342, 752. http://dx.doi.org/10.1016/0140-6736(93)91748-B

[7] Hebert, J.R., Hurley, T.G., Olendszki, B.C., Teas, J., et al. (1998) Nutritional and Socioeconomic Factors in Relation to Prostate Cancer Mortality: A Cross National Study. Journal of the National Cancer Institute, 90, 1637-1647. http://dx.doi.org/10.1093/jnci/90.21.1637

[8] Morton, M.S., Griffiths, K. and Blacklock, N. (1996) The Preventive Role of Diet in Prostatic Disease. British Journal of Urology, 77, 481-493. http://dx.doi.org/10.1046/j.1464-410X.1996.09361.x

[9] Yip, I., Heber, D. and Aronson, W. (1999) Nutrition and Prostate Cancer. Urologic Clinics of North America, 26, 403441. http://dx.doi.org/10.1016/S0094-0143(05)70079-3

[10] Zheng, Y., Zhou, H., Ooi, L.L., Snir, A.D., et al. (2011) Vitamin D Deficiency Promotes Prostate Cancer Growth in Bone. Prostate, 71, 1012-1021. http://dx.doi.org/10.1002/pros.21316

[11] El Touny, L.H. and Banerjee, P.P. (2009) Identification of a Biphasic Role for Genistein in the Regulation of Prostate Cancer Growth and Metastasis. Cancer Research, 69, 3695-3703. http://dx.doi.org/10.1158/0008-5472.CAN-08-2958

[12] Karantanos, T., Corn, P.G. and Thompson, T.C. (2013) Prostate Cancer Progression after Androgen Deprivation Therapy: Mechanisms of Castrate Resistance and Novel Therapeutic Approaches. Oncogene, 32, 5501-5511. http://dx.doi.org/10.1038/onc.2013.206

[13] MacVicar, G.R. and Hussain, M.H. (2013) Emerging Therapies in Metastatic Castration Sensitive and Castration Resistant Prostate Cancer. Current Opinion in Oncology, 25, 252-260.

[14] Singh, P., Uzgare, A., Litvinov, I., Denmeade, S.R., et al. (2006) Combinatorial Androgen Receptor Targeted Therapy for Prostate Cancer. Endocrine-Related Cancer, 13, 653-666. http://dx.doi.org/10.1677/erc.1.00797

[15] Corona, G., Baldi, E. and Maggi, M. (2011) Androgen Regulation of Prostate Cancer, Where Are We Now? Journal of Endocrinological Investigation, 34, 232-243.

[16] Arnold, J.T. and Isaacs, J.T. (2002) Mechanisms Involved in the Progression of Androgen Independent Prostate Cancers: It Is Not Only the Cancer Cell’s Fault. Endocrine-Related Cancer, 9, 61-73. http://dx.doi.org/10.1677/erc.0.0090061

[17] Sandhu, G.S., Nepple, K.G., Tanagho, Y.S. and Andriole, G.L. (2013) Prostate Cancer Chemoprevention. Seminars in Oncology, 40, 276-285. http://dx.doi.org/10.1053/j.seminoncol.2013.04.003

[18] Sebastiano, C., Vincenzo, F., Tommaso, C., Giusseppe, S., et al. (2012) Dietary Patterns and Prostatic Diseases. Frontiers in Bioscience (Elite Edition), 4, 195-204. http://dx.doi.org/10.2741/E369

[19] Schmid, H.P., Fischer, C., Engeler, D.S., Bendhack, M.L., et al. (2011) Nutritional Aspects of Primary Prostate Cancer Prevention. Recent Results in Cancer Research, 188, 101-107. http://dx.doi.org/10.1007/978-3-642-10858-7_8

[20] Isiopoulos, C., Hodge, A. and Kaimakamis, M. (2009) Can Mediterranean Diet Prevent Prostate Cancer? Molecular Nutrition \& Food Research, 53, 227-239. http://dx.doi.org/10.1002/mnfr.200800207

[21] Parsons, J.K., Newman, V.A., Mohler, J.L., Pierce, J.P., et al. (2009) Dietary Intervention after Definitive Therapy for Localized Prostate Cancer: Results from a Pilot Study. The Canadian Journal of Urology, 16, 4648-4654.

[22] Tamler, R. and Mechanick, J.I. (2007) Dietary Supplements and Neutraceuticals in the Management of Andrologic Disorders. Endocrinology and Metabolism Clinics of North America, 36, 533-552. http://dx.doi.org/10.1016/j.ecl.2007.03.005

[23] Dorai, T., Gehani, N. and Katz, A. (2000) Therapeutic Potential of Curcumin in Human Prostate Cancer I. Curcumin Induces Apoptosis in Both Androgen Dependent and Androgen Independent Prostate Cancer Cells. Prostate Cancer and Prostatic Diseases, 3, 84-93. http://dx.doi.org/10.1038/sj.pcan.4500399

[24] Dorai, T., Gehani, N. and Katz, A. (2000) Therapeutic Potential of Curcumin in Human Prostate Cancer II. Curcumin Inhibits the Tyrosine Kinase Activity of Epidermal Growth Factor Receptor and Depletes the Protein. Molecular Urology, 4, 1-6.

[25] Dorai, T., Cao, Y., Dorai, B., Buttyan, R., et al. (2001) Therapeutic Potential of Curcumin in Human Prostate Cancer III. Curcumin Inhibits the Proliferation, Induces Apoptosis and Inhibits Angiogenesis of LNCaP Prostate Cancer Cells in Vivo. The Prostate, 47, 293-303. http://dx.doi.org/10.1002/pros.1074

[26] Dorai, T., Dutcher, J.P., Dempster, D.W. and Wiernik, P.H. (2004) Therapeutic Potential of Curcumin in Prostate Cancer IV: Interference with the Osteomimetic Properties of Hormone Refractory C4-2B Prostate Cancer Cells. The Prostate, 60, 1-17. http://dx.doi.org/10.1002/pros.10359

[27] Dorai, T. and Aggarwal, B.B. (2004) Role of Chemopreventive Agents in Cancer Therapy. Cancer Letters, 215, 129- 
140. http://dx.doi.org/10.1016/j.canlet.2004.07.013

[28] Gupta, S.C., Sung, B., Kim, J.H., Prasad, S., et al. (2013) Multitargeting by Turmeric, the Golden Spice: From Kitchen to Clinic. Molecular Nutrition \& Food Research, 57, 1510-1528. http://dx.doi.org/10.1002/mnfr.201100741

[29] Ravindran, J., Prasad, S. and Aggarwal, B.B. (2009) Curcumin and Cancer Cells; How Many Ways Can Curry Kill Tumor Cells Selectively? The AAPS Journal, 11, 495-510. http://dx.doi.org/10.1208/s12248-009-9128-x

[30] Aggarwal, B.B. (2008) Prostate Cancer and Curcumin: Add Spice to Your Life. Cancer Biology \& Therapy, 7, 14361440. http://dx.doi.org/10.4161/cbt.7.9.6659

[31] Koeneman, K.S., Yeung, F. and Chung, L.W.K. (1999) Osteomimetic Properties of Prostate Cancer Cells: A Hypothesis Supporting the Predilection of Prostate Cancer Metastasis and Growth in the Bone Environment. The Prostate, 39, 246-261. http://dx.doi.org/10.1002/(SICI)1097-0045(19990601)39:4<246::AID-PROS5>3.0.CO;2-U

[32] Thalmann, G.N., Sikes, R.A., Wu, T.T., Degeorges, A., et al. (2000) LNCaP Progression Model of Human Prostate Cancer: Androgen Independence and Osseous Metastasis. The Prostate, 44, 91-103.

[33] Josson, S., Matsuoka, Y., Chung, L.W.K., Zhau, H.E., et al. (2010) Tumor-Stroma Co-Evolution in Prostate Cancer Progression and Metastasis. Seminars in Cell \& Developmental Biology, 21, $26-32$. http://dx.doi.org/10.1016/j.semcdb.2009.11.016

[34] Buijs, J.T., Rentsch, C.A., van der Horst, G., van Overveld, P.G.M., et al. (2007) BMP-7, A Putative Regulator of Epithelial Homeostasis in Human Prostate, Is a Potent Inhibitor of Prostate Cancer Bone Metastasis in Vivo. American Journal of Pathology, 171, 1047-1057. http://dx.doi.org/10.2353/ajpath.2007.070168

[35] Corey, E., Quinn, J.E., Bladou, F., Brown, L.G., et al. (2002) Establishment and Characterization of Osseous Prostate Cancer Models: Intra-Tibial Injection of Human Prostate Cancer Cells. The Prostate, 52, 20-33. http://dx.doi.org/10.1002/pros.10091

[36] Liu, C.C., Sherrard, D.J., Maloney, N.A. and Howard, G.A. (1980) Reactivation of Inhibited Bone Acid Phosphatase and Its Significance in Bone Histomorphometry. Journal of Histochemistry \& Cytochemistry, 35, 1355-1363. http://dx.doi.org/10.1177/35.12.3680930

[37] Wu, J., Cohen, P. and Spiegelman, B.M. (2013) Adaptive Thermogenesis in Adipocytes: Is Beige the New Brown? Genes \& Development, 27, 234-250. http://dx.doi.org/10.1101/gad.211649.112

[38] Weilbaecher, K.N., Guise, T.A. and McCauley, L.K. (2011) Cancer to Bone: A Fatal Attraction. Nature Reviews Cancer, 11, 411-425. http://dx.doi.org/10.1038/nrc3055

[39] Guise, T.A. (2013) Breast Cancer Metastases: It’s All in the Neighborhood. Cell, 154, 957-959. http://dx.doi.org/10.1016/j.cell.2013.08.020

[40] Juarez, P. and Guise, T.A. (2011) TGF- $\beta$ in Cancer and Bone: Implications for Treatment of Bone Metastases. Bone, 48, 23-29. http://dx.doi.org/10.1016/j.bone.2010.08.004

[41] Buijs, J.T., Stayrook, K.R. and Guise, T.A. (2011) TGF- $\beta$ in the Bone Microenvironment: Role in Breast Cancer Metastases. Cancer Microenvironment, 4, 261-281. http://dx.doi.org/10.1007/s12307-011-0075-6

[42] Buijs, J.T., Henriquez, N.V., van Overveld, van der Horst, G., et al. (2007) TGF- $\beta$ and BMP-7 Interactions in Tumor Progression and Bone Metastasis. Clinical and Experimental Metastasis, 24, 609-617. http://dx.doi.org/10.1007/s10585-007-9118-2

[43] Buijs, J.T., Petersen, M., van der Horst, G. and van der Pluijm, G. (2010) Bone Morphogenic Proteins and Their Receptors: Therapeutic Targets in Cancer Progression and Bone Metastasis. Current Pharmaceutical Design, 16, 12911300. http://dx.doi.org/10.2174/138161210791033987

[44] Buijs, J.T. and van der Pluijm, G. (2009) Osteotrophic Cancers: From Primary Tumor to Bone. Cancer Letters, 273, 177-193. http://dx.doi.org/10.1016/j.canlet.2008.05.044

[45] Buijs, J.T., Henriquez, N.V., van Overveld, P.G., van der Horst, G., et al. (2007) Bone Morphogenic Protein 7 in the Development and Treatment of Bone Metastases from Breast Cancer. Cancer Research, 67, 8742-8751. http://dx.doi.org/10.1158/0008-5472.CAN-06-2490

[46] Lin, D.L., Tarnowski, C.P., Zhang, J., Dai, J., et al. (2001) Bone Metastastic LNCaP Derivative C4-2B Prostate Cancer Cell Line Mineralizes in Vitro. The Prostate, 47, 212-221. http://dx.doi.org/10.1002/pros.1065

[47] Kunnumakkara, A.B., Anand, P. and Aggarwal, B.B. (2008) Curcumin Inhibits Proliferation, Invasion, Angiogenesis and Metastasis of Different Cancers through Interaction with Multiple Cell Signaling Proteins. Cancer Letters, 269, 199-225. http://dx.doi.org/10.1016/j.canlet.2008.03.009

[48] Jacob, A., Wu, R., Zhou, M. and Wang, P. (2007) Mechanism of the Anti-Inflammatory Effect of Curcumin: PPAR- $\gamma$ Activation. PPAR Research, 89369.

[49] Kiss, E., Popovic, Z.V., Bedke, J., Adams, J., et al. (2010) Peroxisome Proliferator-Activated Receptor (PPAR)- $\gamma$ Can Inhibit Chronic Renal Allograft Damage. American Journal of Pathology, 176, 2150-2162. 
http://dx.doi.org/10.2353/ajpath.2010.090370

[50] Shezad, A., Ha, T., Subhan, F. and Lee, Y.S. (2011) New Mechanisms and the Anti-Inflammatory Role of Curcumin in Obesity and Obesity Related Metabolic Diseases. European Journal of Nutrition, 50, 151-161. http://dx.doi.org/10.1007/s00394-011-0188-1

[51] Dandawate, P., Padhye, S., Ahmad, A. and Sarkar, F.H. (2013) Novel Strategies Targeting Cancer Stem Cells through Phytochemicals and Their Analogues. Drug Delivery and Translational Research, 3, 165-182. http://dx.doi.org/10.1007/s13346-012-0079-x

[52] Bradford, P.G. (2013) Curcumin and Obesity. Biofactors, 39, 78-87. http://dx.doi.org/10.1002/biof.1074

[53] Gonzales, A.M. and Orlando, R.A. (2008) Curcumin and Resveratrol Inhibit Nuclear Factor-KappaB-Mediated Cytokine Expression in Adipocytes. Nutrition \& Metabolism (Lond), 5, 17.

[54] Aggarwal, B.B. (2010) Targeting Inflammation-Induced Obesity and Metabolic Diseases by Curcumin and Other Neutraceuticals. Annual Review of Nutrition, 30, 173-199. http://dx.doi.org/10.1146/annurev.nutr.012809.104755

[55] Shao, W., Yu, Z., Chiang, Y., Yang, Y., et al. (2012) Curcumin Prevents High Fat Diet Induced Insulin Resistance and Obesity via Attenuating Lipogenesis in Liver and Inflammatory Pathway in Adipocytes. PLoS One, 7, e28784. http://dx.doi.org/10.1371/journal.pone.0028784

[56] Wang, S., Moustaid-Moussa, N., Chen, L., Mo, H., et al. (2014) Novel Insights of Dietary Polyphenols and Obesity. The Journal of Nutritional Biochemistry, 25, 1-18. http://dx.doi.org/10.1016/j.jnutbio.2013.09.001

[57] Muruganandan, S., Roman, A.A. and Sinal, C.J. (2009) Adipocyte Differentiation of Bone Marrow-Derived Mesenchymal Stem Cells: Cross Talk with the Osteoblastogenic Program. Cellular and Molecular Life Sciences, 66, $236-253$. http://dx.doi.org/10.1007/s00018-008-8429-z

[58] Takada, I., Kouzmenko, A.P. and Kato, S. (2009) Wnt and PPAR- $\gamma$ Signaling in Osteoblastogenesis and Adipogenesis. Nature Reviews Rheumatology, 5, 442-447. http://dx.doi.org/10.1038/nrrheum.2009.137

[59] Takada, I., Suzawa, M., Matsumoto, K. and Kato, S. (2007) Suppression of PPAR Transactivation Switches Cell Fate of Bone Marrow Stem Cells from Adipocytes into Osteoblasts. Annals of the New York Academy of Sciences, 1116, 182-195.http://dx.doi.org/10.1196/annals.1402.034

[60] Zhang, H., Lu, W., Zhao, Y., Rong, P., et al. (2011) Adipocytes Derived from Human Bone Marrow Mesenchymal Stem Cells Exert Inhibitory Effects on Osteoblastogenesis. Current Molecular Medicine, 11, 489-502. http://dx.doi.org/10.2174/156652411796268704

[61] Schilling, T., Noth, U., Klein-Hitpass, L., Jacob, F., et al. (2007) Plasticity in Adipogenesis and Osteogenesis of Human Mesenchymal Stem Cells. Molecular and Cellular Endocrinology, 271, 1-17. http://dx.doi.org/10.1016/j.mce.2007.03.004

[62] Giralt, M., Villarroya, F., White, B. and Biege, B. (2013) Different Adipose Cells for Different Functions? Endocrinology, 154, 2992-3000. http://dx.doi.org/10.1210/en.2013-1403

[63] Wright, L.E., Frye, J.B., Lukefahr, A.L., Timmermann, B.N., et al. (2013) Curcuminoids Sblock TGF- $\beta$ Signaling in Human Breast Cancer Cells and Limit Osteolysis in a Murine Model of Breast Cancer Bone Metastasis. Journal of Natural Products, 76, 316-321. http://dx.doi.org/10.1021/np300663v

[64] Moerman, E.J., Teng, K., Lipschitz, D.A. and Lecka-Czernik, B. (2004) Aging Activates Adipogenic and Suppresses Osteogenic Programs in Mesenchymal Marrow Stromal/Stem Cells: The Role of PPAR Gamma 2 Transcription Factor and TGF- $\beta$ /BMP Signaling Pathways. Aging Cell, 3, 379-389. http://dx.doi.org/10.1111/j.1474-9728.2004.00127.x

[65] Zheng, S. and Chen, A. (2007) Disruption of Transforming Growth Factor-Beta Signaling by Curcumin Induces Gene Expression of Peroxisome Proliferator-Activated Receptor- $\gamma$ in Rat Hepatic Stellate Cells. American Journal of Physiology_Gastrointestinal and Liver Physiology, 292, G113-G123. http://dx.doi.org/10.1152/ajpgi.00200.2006

[66] Morrissey, C., Brown, L.G., Pitts, T.E.M., Vessella, R.L., et al. (2010) Bone Morphogenic Protein 7 Is Expressed in Prostate Cancer Metastases and Its Effects on Prostate Tumor Cells Depend on Cell Phenotype and the Tumor Microenvironment. Neoplasia, 12, 192-205.

[67] Boon, M.R., van der Horst, G., van der Pluijm, G., Tamsma, J.T., et al. (2011) Bone Morphogenic Protein-7: A BroadSpectrum Growth Factor with Multiple Target Therapeutic Potency. Cytokine \& Growth Factor Reviews, 22, 221-229. http://dx.doi.org/10.1016/j.cytogfr.2011.08.001

[68] Silverman, S.L. and Landesberg, R. (2009) Osteonecrosis of the Jaw and the Role of Bisphosphonates: A Critical Review. American Journal of Medicine, 122, S33-S45. http://dx.doi.org/10.1016/j.amjmed.2008.12.005

[69] Anand, P. and Kunnumakkara, A.B., Newman, R.A. and Aggarwal, B.B. (2007) Bioavailability of Curcumin, Problems and Promises. Molecular Pharmacology, 4, 807-818. http://dx.doi.org/10.1021/mp700113r

[70] Morgan, S.C. and Parker, C.C. (2011) Local Treatment of Metastatic Cancer-Killing the Seed or Disturbing the Soil? Nature Reviews Clinical Oncology, 8, 504-506. http://dx.doi.org/10.1038/nrclinonc.2011.88 